\title{
Determination between transmission wave field of in-seam seismic survey and thickness of coal seam
}

\author{
Songying Li, Jie Lian, Xiaoshuai Yao, Kang Wang \\ Geological Institute \\ Yima Coal Industry Group Co., Ltd \\ Yima, China \\ Lsy161@sohu.com \\ Jiwen Teng \\ Institute of Geology and Geophysics \\ Chinese Academy of Sciences \\ Beijing, China
}

\author{
Jie Lian, Feng Lei, Xiaoshuai Yao \\ School of Resource\& Environment \\ Henan Polytechnic University \\ Jiaozuo, China
}

\begin{abstract}
Taking advantage of the research results of the transmission wave field response in in-seam seismic survey(ISS), and according to the related laws between the L-wave dispersion characteristics and the seam thickness, the technology based on the transmission method of ISS has been developed for quantitative detection of coal seam thickness, and the such experiments had been carried out in Yima mining area, HenNan province., where the coal seam thickness is $2.2 \mathrm{~m}$. the tomographic image was formed by $185 \mathrm{~Hz}$, then 5 thin coal zones were circled in which the thickness is less than $1.5 \mathrm{~m}$. The forecast accuracy was verified by mining and reconstruction recorder. It was put forward that the transmission method of ISS have realized high precision detection of coal seam thickness and can be used to guide the safe and efficient production in coalmine.
\end{abstract}

Keywords—in-seam seismic survey(ISS); transmission method; L-wave; coal seam thickness; dispersion

\section{INTRODUCTION}

It is a hot issue in coal-mining industry that how to accurately and efficiently determine coal seam thickness and its variation in working face. 3D seismic survey could be also applied for exploring the coal seam thickness which is helpful for design of district and working face, nonetheless, the detected results are hardly applied for mining guidance because of long distance to coal seam, susceptible to overlying rock and topographic condition and low precision. Radio wave penetration system is the common method in coal seam thickness variation exploration, which could be realized qualitative analysis of coal seam thickness, not quantitative interpretation, therefore the way cannot meet the demand of precise exploration.

In-seam seismic wave was excited and recorded in Mangapehi coal mine in New Zealand by Evison for the first time in $1995^{[1]}$. In 1963, it was demonstrated that In-seam seismic wave exist in coal seam both in theory and practice by Krey from Germany, ${ }^{[2]}$ and the application value of in seam seismic wave was firstly presented. Theoretical research and instrument development of In-seam seismic developed fast abroad in 70s of last century. Good application results had been made in structure detection by ISS in countries like Germany, Britain and Australia in 80s. ISS was rarely used for detecting coal seam thickness variation, because occurrence condition of coal seam in foreign countries was much simpler than in China. Plenty of research and practice works had been done in China after introducing ISS technology from 1977, then the technology made slower progress, even stagnate, and was never applied for coal seam thickness detection in high precision and quantitative interpretation, by the reasons of coal market slump, poor benefits and heavier equipment, complicated operation and difficult interpretation etc.. In order to solve the problem in detecting coal seam thickness variation, SUMMIT- II EX In-seam seismic recorder had been firstly introduced by Yima Coal Industry Group in China in 2010. ISS projects had been carried out more than 50 times, and formed a technique of quantitative exploration and interpretation, which guided underground mining in safety and high efficiency in Yima.

\section{METHOD AND PRINCIPLES}

\section{A. Detection Method}

ISS was carried out with drilling blast holes of 2 meters depth in one roadway, and drilling the holes for installing geophones in 2 meters depth in another roadway by transmission method with SUMMIT- II EX. Geophones mainly receive L-wave. In order to acquire good data, blast holes and geophone holes could be drilled in the middle of coal seam as possible. Blast holes should be filled with clay after installing explosives and detonators, and the geophones must be inflated so as to ensure that gasbags were close to the wall of hole.

\section{B. Detection Principles}

The geophones with 2 component of In-seam seismic recorder in SUMMIT- II EX mainly receive L-wave with few R-wave. Previous scholars had already derived the dispersion equation of L-wave in symmetry model with 3 layers. 


$$
\begin{aligned}
& \frac{\omega d}{c_{L}} \sqrt{c_{L}^{2} / v_{S 1}^{2}-1}=\arctan \left[\frac{\mu_{1}}{\mu_{2}} \frac{\sqrt{1-c_{L}^{2} / v_{\mathrm{S} 1}^{2}}}{\sqrt{c_{L}^{2} / v_{S 2}^{2}-1}}\right]+n \pi, \\
& n=0,1,2, \cdots .
\end{aligned}
$$

In this equation, $d$ represents half of coal seam thickness, whose unit is meter. $v_{s 1}$ and $v_{s 2}$ respectively represent velocity of $\mathrm{S}$ wave of surrounding rock and coal seam, whose unit is $\mathrm{m} \cdot \mathrm{s}^{-1} . \mu_{1}$ and $\mu_{2}$ respectively represent the shear modulus of surrounding rock and coal seam. $\omega$ represents circular frequency. $c_{L}$ represents the phase velocity of L-wave.

According to the equation, the curve that the velocity of channel wave in different coal seam thickness changes with frequency could be got. Impact of dispersion curve of L-wave caused by coal seam thickness variation shows that dominant frequency zone of L-wave moving to low frequency, and velocity in same frequency also become lower from Fig.1. There is a negative correlation between coal seam thickness and velocity of channel wave, it means that velocity of channel wave is higher in thin coal zone, otherwise, the velocity is lower. Then computed tomography is carried out in suitable frequency, and velocity of channel wave was compared and fitted with the exposed coal seam thickness, and the correspondence between velocity and coal seam thickness was achieved. Finally, the coal seam thickness contour of working face could be drawn from velocity of channel wave.

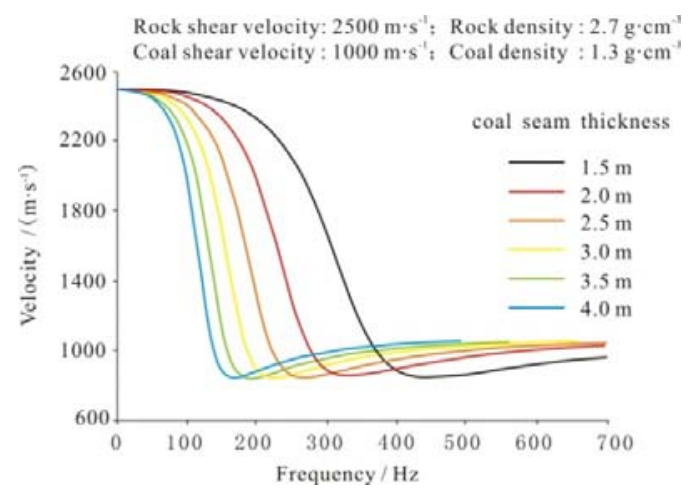

Fig. 1 Dependency of dispersion from coal seam thickness (symmetrical model)

\section{APPLiCATIONS}

\section{A. Example 1}

\section{1) Working Face Profiles:}

Strike length of working face 15200 is $1054 \mathrm{~m}$, and dip width is $225 \mathrm{~m}$ in Huaxing coal mine. The coal seam thickness is from $0.2 \mathrm{~m}$ to $7.8 \mathrm{~m}$ with an average of $2.2 \mathrm{~m}$, and the variable coefficient is 73 percent, and the coal seam is an extremely unstable seam. Dip angle of the coal seam is $15^{\circ}$. Coal seam is powdery with simple structure and less gangues. The false roof, local existing, is mudstone or sandy mudstone with thickness from $0.2 \mathrm{~m}$ to $0.5 \mathrm{~m}$. The immediate roof is sandstone with average thickness of $14.5 \mathrm{~m}$. The immediate bottom is mudstone with thin fine sandstone and siltstone.

The section with $320 \mathrm{~m}$ length which had been already mined without ISS in working face 15200, in which the coal seam thickness variation was unclear, so that blind transformation caused the roadway of 600 lengths scraped. Above reasons led to low production efficiency and bad coal quality.

\section{2) Design of Observation System:}

Mining condition of working face 15200 was complicated, and the face was divided into 3 parts by middle roadway and crossheading. According to the condition, the project included 3 areas, A, B and C. This article took A as example (Fig.2).

34 blast holes were drilled in the upper roadway in working face 15200 with hole distance of $15 \mathrm{~m}$. 15 blast holes were drilled in cutting hole with distance of $10 \mathrm{~m}$. 30 geophone holes were drilled in middle roadway with distance of $20 \mathrm{~m}$.

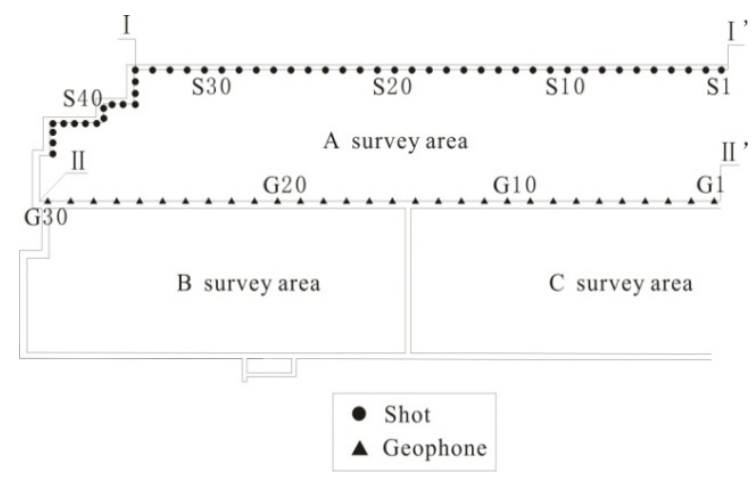

Fig. 2 Layout of observation system in A area of 15200 working face

\section{3) Data Collection and Recognition:}

44 shots were valid in the exploration by transmission method in working face 15200, and 26 geophone points were valid. Shots from S1 to S3, S6 and S30 were not drilled because of bad condition, and the geophone points of G1 、 G2、 G26 and G30 were invalid.

Raw data showed that data quality of this exploration was bad, and channel wave of most data were not obvious. For example, there were not clear channel wave from G1 to G10 and G19 to G30 in shot 14, and only the data from G11 to G18 were obvious (Fig.3). In the end, 301 data of which the channel wave were clear had been recognized from 1144 .

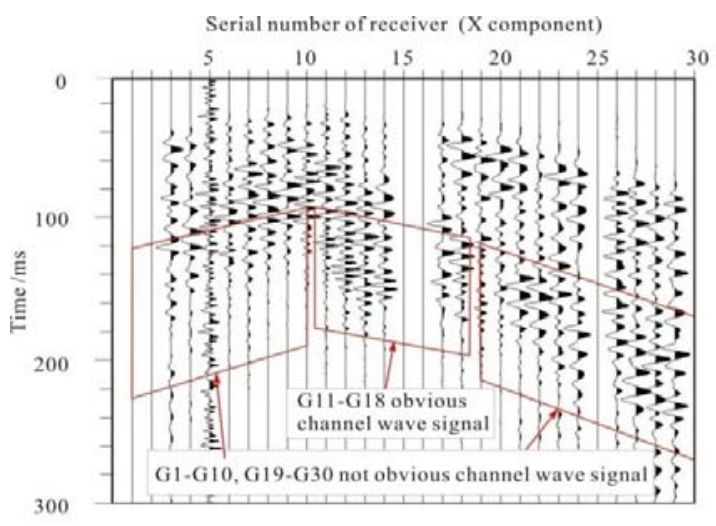

Fig. 3 Seismic record of shot 14 
4) CT in Suitable Frequency:

It was indicated that the channel wave in high frequency had better resolution for thin coal area of which the coal seam thickness was less than $1.5 \mathrm{~m}$ than in low frequency based on the correlation between dispersion curve of L-wave and coal seam thickness variation in single seam. By dispersion analysis of actual data, $185 \mathrm{~Hz}$ was selected as the suitable frequency for picking up the group velocity of 301 data recognized from data in section A, then velocity of channel wave was acquired by CT in $185 \mathrm{~Hz}$ in working face 15200 (Fig.4).

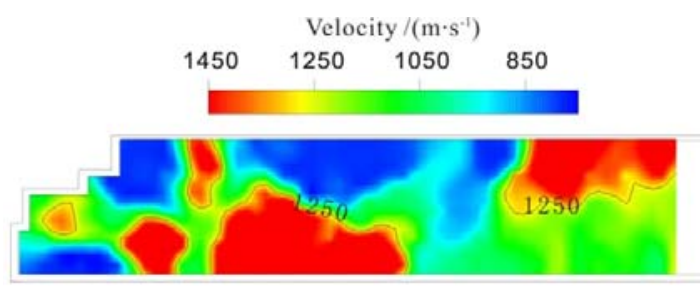

Fig. 4 Velocity of channel wave in 15200 working face

\section{5) Interpretation of Coal Seam Thickness}

Based on coal seam thickness exposed by roadway and result from CT, fourth order polynomial was used for fitting relation curve of velocity-thickness, and the line of the velocity of channel wave in $1250 \mathrm{~m} / \mathrm{s}$ was regard as the boundary of the thin coal area where the thickness was less than $1.5 \mathrm{~m}$ (Fig.5). Finally, 5 areas had been circled.

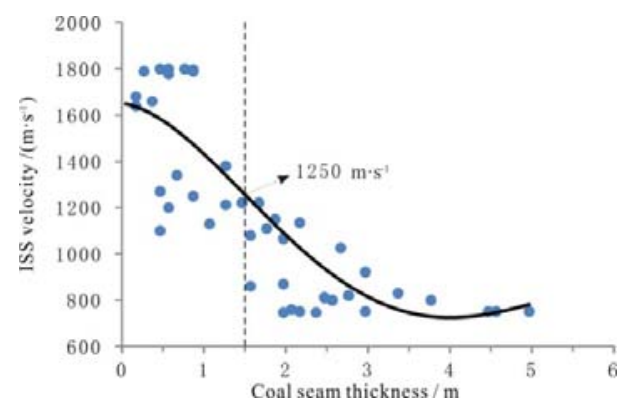

Fig. 5 Fitting curve of coal seam thickness and velocity

\section{6) Verification:}

According to exploration result, modification plan was optimized, and working face 15200 has been mined with scientific guidance avoiding blind transformation. Compared with the information of coal seam thickness exposed by exploration entry, modification roadways, and mining. The coal seam thickness of 101 points accorded with prediction from 120, and the verification accuracy ratio reached to 84 percent (Fig.6).

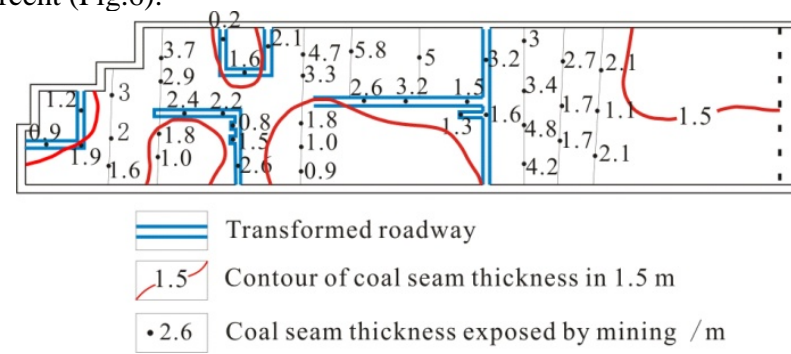

Fig. 6 Thickness comparison between prediction and actuality

\section{B. Example 2}

1) Working Face Profiles :

Strike length of working face 11061 is $1090 \mathrm{~m}$, and dip width is $135 \mathrm{~m}$ in Yian coal mine. Recoverable reserves were 1.07 million tons. Coal seam thickness of the working face is from $0.4 \mathrm{~m}$ to $8 \mathrm{~m}$ with an average of $4.5 \mathrm{~m}$, and the coal seam is an unstable seam. The false roof, local existing, is thin carbon mudstone. The immediate roof is sandy mudstone and finemedium-grained quartzose sandstone with average thickness of $18 \mathrm{~m}$. The immediate bottom is powder-fine sandstone with average thickness of $7 \mathrm{~m}$.

\section{2) Design of Observation System:}

The section of $450 \mathrm{~m}$ long from the stopping line had been explored by ISS in working face 11061. 22 geophone holes had been drilled in transportation roadway with distance of 20 $\mathrm{m} 36$ blast holes had been drilled in the track roadway with distance of $10 \mathrm{~m}$.

\section{3) Data Collection and Recognition:}

The exploration design included 36 blast points and 22 geophone points while the collecting data included 34 shots and 22 geophone points, and shot 4 and shot 11 were invalid. Raw data showed that channel wave of most data were obvious, and dispersion curve of the channel wave were clear. 410 data of which the channel wave were clear had been recognized from 546 (Fig.7).

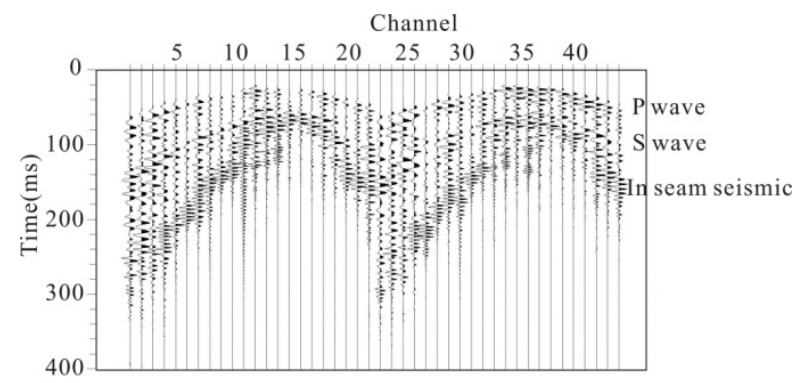

Fig. 7 Seismic record of shot 26

\section{4) CT in Suitable Frequency:}

It was indicated that the channel wave in low frequency had better resolution for thick coal area while in high frequency had better resolution for thin coal area based on the correlation between dispersion curve of L-wave and coal seam thickness variation in single seam. The coal seam thickness mostly exposed by roadway was between $3.0 \mathrm{~m}$ and $5.0 \mathrm{~m}$, therefore, $125 \mathrm{~Hz}$ was selected as the suitable frequency for CT in consideration of the dispersion of actual data. (Fig.8).

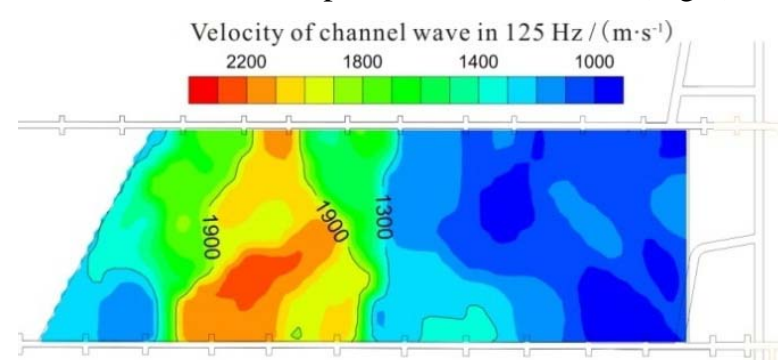

Fig. 8 Velocity distribution of channel wave of 11061 working face 
5) Interpretation of Coal Seam Thickness:

Based on coal seam thickness exposed by roadway and result from CT, coal seam thickness was fitted for velocity of channel wave, and the results showed that: coal seam occurrence condition was good, and it was only a small part where coal seam thickness was less than $3 \mathrm{~m}$. Coal seam thickness was more than $3 \mathrm{~m}$ in the red zone where the velocity were equal or more than $1900 \mathrm{~m} / \mathrm{s}$, and the red zone was 19 percent of exploration area. Coal seam thickness was more than $5 \mathrm{~m}$ in blue zone where the velocity were less than 1300 $\mathrm{m} / \mathrm{s}$, and the blue zone was 57 percent of exploration area. Coal seam thickness was between $3 \mathrm{~m}$ and $5 \mathrm{~m}$ in the zone where the velocity was between 1300 and $1900 \mathrm{~m} / \mathrm{s}$, and the zone was 24 percent of exploration area (Fig.9).

\section{6) Verification}

The working face had been already mined, and the accuracy ratio of prediction reached to 85 percent by comparing the exploration results with actual coal seam thickness (Fig.9).

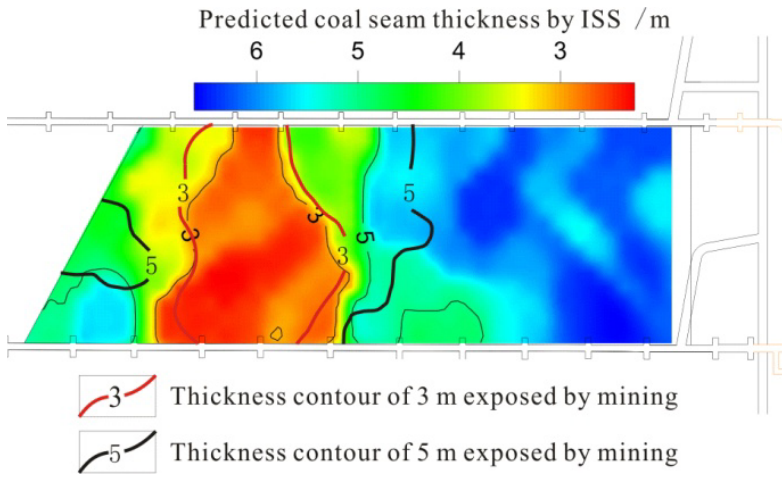

Fig. 9 Comparison of coal seam thickness between prediction and actuality

\section{CONCLUSIONS}

Impact of dispersion curve of L-wave caused by coal seam thickness variation showed that dominant frequency zone of Lwave moved to low frequency. The channel wave in high frequency had better resolution for thin coal area while in low frequency had better resolution for thick coal area. Good interpretation had been got by CT.

In specific frequency, the negative correlation between coal seam thickness and velocity of channel wave showed that velocity decreased as thickness increasing. CT was carried out in suitable frequency, and the velocity of channel wave was fitted with actual coal seam thickness exposed by roadway. Finally, quantitative coal seam thickness of working face could be achieved.

\section{REFERENCES}

[1] Evison F F. A coal seam as a guide for seismic energy. Nature,1955, 176 (4495): :1224-1225.

[2] Krey T C. Channel waves as a tool of applied geophysics in coal mining. Geophysics, 1963,28（5）:701-704. 